\title{
POSTERIOR DISLOCATION OF THE SHOULDER ASSOCIATED WITH OBSTETRIC BRACHIAL PLEXUS PALSY
}

\author{
M. C. DUNKERTON
}

\section{From St Mary's Hospital, London}

\begin{abstract}
Four cases of posterior dislocation of the shoulder at birth in association with obstetric brachial plexus palsy are presented. Review of the literature suggests that this association is not generally recognised. All cases were diagnosed late; two were treated by open reduction, one by humeral osteotomy and one managed conservatively.
\end{abstract}

Posterior dislocation of the shoulder is not generally recognised as a birth injury associated with obstetric brachial plexus palsy. Wickstrom, Haslam and Hutchinson (1955) described five cases of posterior dislocation occurring late as a result of muscle imbalance. More recent reports describe anterior dislocation during birth (Angeletti 1970; Chari, Rao and Rao 1979).

With improved obstetric care, this type of injury has become less frequent but the diagnosis of posterior dislocation may be missed unless considered. Four such cases are presented with the common feature of obstetric difficulty involving the shoulder. Two of the babies were overweight. A confirmed diagnosis of obstetric brachial plexus palsy was made in three cases; in the fourth there was evidence of a resolving Erb's palsy.

\section{CASE REPORTS}

Case 1. A nine-month-old infant was referred with a resolving Erb's palsy. He had been born at full term weighing $10 \mathrm{lb} 10 \mathrm{oz}$ and delivered with extreme difficulty. The plexus lesion was initially complete, but the hand recovered by seven months. Radiographs taken at six months showed posterior dislocation of the shoulder. Open reduction was performed by a posterior approach and at the same time, exploration of the plexus by a supraclavicular incision confirmed a lesion in continuity.

A year after exploration, the child had good recovery of biceps and deltoid, but the lateral rotators of the shoulder remained paralysed. There was good passive forward flexion of the shoulder, but abduction was restricted to $85^{\circ}$, and $20^{\circ}$ of fixed medial rotation persisted.

M. C. Dunkerton, FRCS, FRCS (Ed), Orthopaedic Senior Registrar St Mary`s Hospital, Praed Street, London W2 INY.

(C) 1989 British Editorial Society of Bone and Joint Surgery $0301-620 \mathrm{X} / 89 / 5178 \$ 2.00$

J Bone Joint Surg [ Br] 1989; 71-B: 764-6.
Further radiographs confirmed that the shoulder remained reduced.

Case 2. A 12-year-old boy recovered well from an obstetric palsy sustained during a difficult birth in Somalia. He had no recovery in the deltoid, but his main handicap was fixed medial rotation of the shoulder. Radiographs showed posterior dislocation of the shoulder (Figs 1 and 2) and he was treated by open reduction using an anterior approach as described by Fairbank (1913). Despite dislocation since birth, the humeral head appeared normal and the glenoid, although small and shaped like an 'hour-glass', was covered by healthy cartilage. The shoulder was stabilised temporarily using Steinmann pins and a plaster spica.

Six months later, shoulder function had improved considerably and the boy had little disability. His deltoid remained paralysed, but the shoulder had a normal range of rotation and the lateral rotators showed reasonable power (MRC grade 4).

Case 3. An eight-year-old boy presented with inability to raise his arm without abducting his shoulder and winging his scapula. On examination he had $15^{\circ}$ medial rotation deformity of the shoulder; radiographs confirmed posterior dislocation. His birth had involved a long and difficult delivery; he had been treated for dislocation of the elbow. His brachial plexus injury and shoulder dislocation had gone unrecognised.

Treatment at the age of 12 years was by a lateral rotation osteotomy of the upper humerus. Three years later he had $30^{\circ}$ of active lateral rotation, although these muscles and the biceps remained weak (MRC grade 4). He had minimal disability, and was able to swim long distances and play squash.

Case 4. A seven-year-old girl presented with limited shoulder movement despite good recovery from an obstetric palsy. Her birth weight was $10 \mathrm{lb} 3 \mathrm{oz}(5.4 \mathrm{~kg})$ and her shoulders had been stuck for one and a half hours during delivery. Her mother remembers the obstetrician 
pulling on a bandage passed under the baby's axilla, and that at first there was complete paralysis of one arm. Finger movement had recovered in a few days, elbow flexion by four months and shoulder movement by one year.

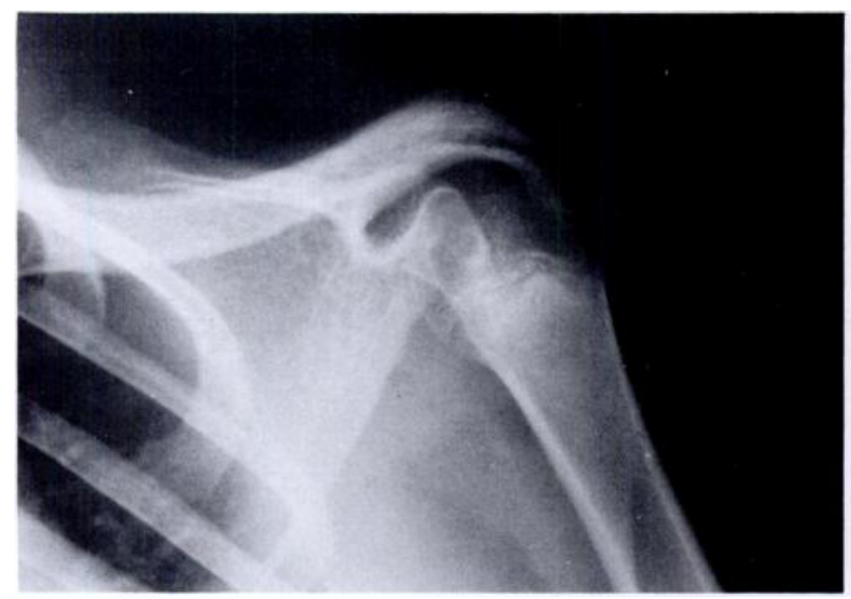

Fig. 1
The most important clinical sign of posterior dislocation is loss of passive lateral rotation beyond neutral; this should immediately alert the examiner. There is the same difficulty of radiographic diagnosis as in adult posterior dislocation: routine anteroposterior

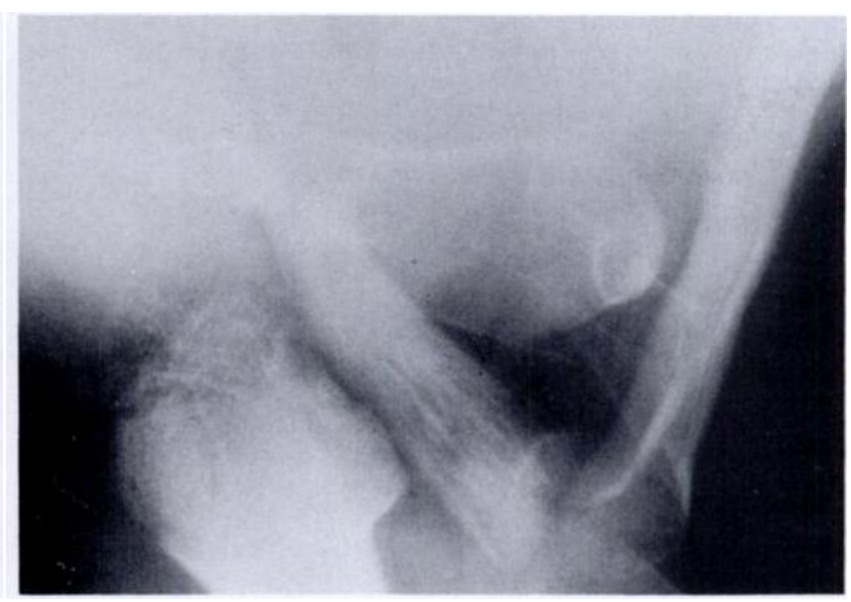

Fig. 2

Case 2. Anteroposterior and axial radiographs of the shoulder showing the humeral head lying posterior to the glenoid.

At seven years the child has weakness of deltoid, infraspinatus and biceps (MRC grade 4) with no passive lateral rotation beyond neutral. Radiographs confirm posterior dislocation (Fig. 3), but at present her case is being managed expectantly.

\section{DISCUSSION}

When a late diagnosis is made of posterior dislocation of the shoulder associated with obstetric brachial plexus palsy, it is uncertain whether the dislocation is a direct result of the birth injury or secondary to nerve injury and muscle imbalance. Wickstrom et al (1955) attributes late dislocation to the latter mechanism and to gradual flattening of the humeral head. Narakas (1987) describes contracture of subscapularis muscle and suggests that this is responsible for late subluxation and dislocation.

There is strong evidence that the dislocations described in this series occurred at birth. In the two cases treated by open reduction there was no evidence of subscapularis contracture and in the second case there was good power in the lateral rotators which became apparent once the dislocation had been reduced. In the third case the neural lesion was mild and, again, strong lateral rotation was demonstrated after operation. At operation, the humeral heads were not distorted and the only evidence of flattening was seen on the axial radiograph of the fourth (unoperated) case; this may well result from damage to the epiphysis rather than muscle imbalance.

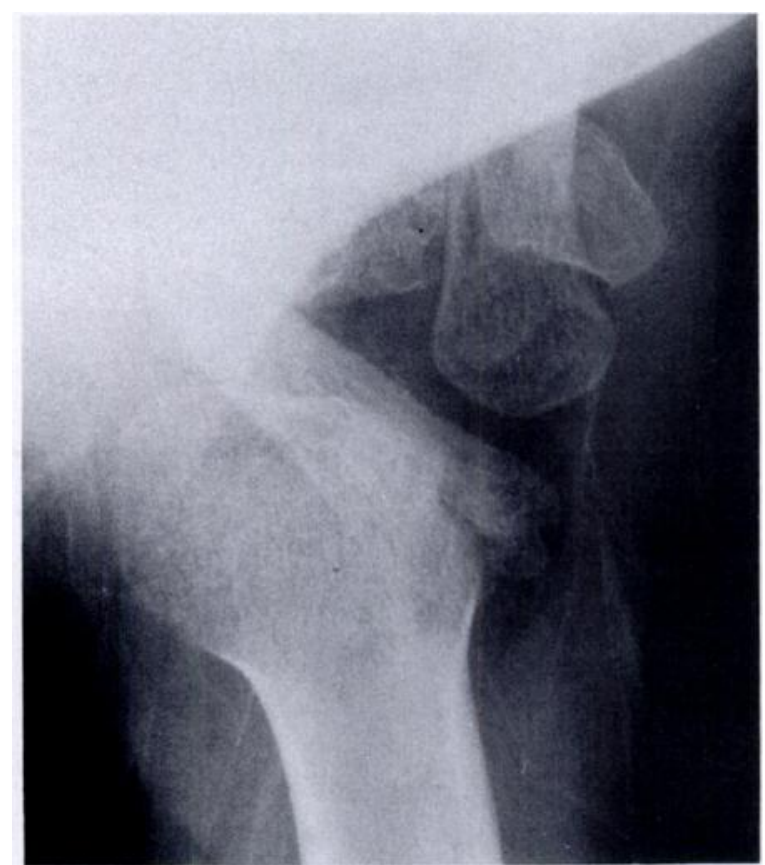

Fig. 3

Case 4. Axial radiograph of the shoulder showing slight flattening of the humeral head.

radiographs may be nearly normal. In these cases, however, the position of the humeral head was obvious on axial views.

Dislocation adds considerably to the loss of function 
in children with recovering Erb's palsy, and its correction by operation results in marked improvement. Open reduction and stabilisation proved surprisingly effective even in very late cases and is preferred as a first option. Lateral rotation osteotomy of the proximal humerus is recommended for salvage of function in older children.

The author wishes to thank Mr S. Copeland, Mr D. Hunt and Mr R. Birch for permission to report their patients and also $\mathrm{Mr}$ George Bonney who made the diagnosis in one case.

No benefits in any form have been received or will be received from a commercial party related directly or indirectly to the subject of this article.

\section{REFERENCES}

Angeletti P. Lussazione anteriore congenit della spalla. Arch Putti Chir Organi Mov 1970; 25:146-55.

Chari PR, Rao YV, Rao BK. Congenital abduction contracture with dislocation of the shoulder in children: a report of two cases. Aust NZ J Surg 1979; 49:105-6.

Fairbank HAT. Birth palsy: A lecture on subluxation of the shoulderjoint in infants and young children. Lancet 1913; i:1217-23.

Narakas AO. Obstetrical brachial plexus injuries. In: Lamb DW, ed. The paralysed hand. The hand and upper limb Vol. 2. Edinburgh, etc: Churchill Livingstone, 1987:116-35.

Wickstrom J, Haslam ET, Hutchinson RH. The surgical management of residual deformities of the shoulder following birth injuries of the brachial plexus. J Bone Joint Surg [ Am] 1955; 37-A :27-36. 